\title{
Low Cycle Fatigue, Creep-Fatigue and Relaxation-Fatigue Tests on P91
}

\author{
Carlo Cristalli, Pietro Agostini, Davide Bernardi, Nicola Bettocchi, Luigi Masotti and Sandro Storai \\ ENEA CR Brasimone, Camugnano (BO) 40032, Italy
}

\begin{abstract}
Creep-fatigue is a damage mechanism where cyclic deformation damage (fatigue) is enhanced by creep damage and vice versa. Factors affecting the creep-fatigue damage are stress level (or, equivalently, strain range), temperature, hold time period, material softening/hardening and number of cycles. Moreover, environmental effects can accelerate the creep-fatigue interaction (oxidation, hot corrosion, irradiation, etc.). The activity described in this paper was planned to perform tests on $9 \mathrm{Cr}-1 \mathrm{Mo}$ ferritic/martensitic steel (P91) combining fatigue cycles and constant tensile and compressive holding periods. A preliminary basic fatigue characterization campaign in the LCF (low cycle fatigue) regime was carried out by performing a series of strain controlled tests, each at the same temperature $\left(550{ }^{\circ} \mathrm{C}\right)$, using two different values for the total strain range $(1 \%$ and $0.6 \%)$ and the same total strain rate $\left(2 \times 10^{-3} \mathrm{~s}^{-1}\right)$. The tests were carried out with a strain ratio of -1 , i.e., in fully reversed cyclic conditions. In this paper we illustrate the results obtained by testing in air P91 $(9 \mathrm{Cr}-1 \mathrm{Mo})$ ferritic/martensitic steel, introducing different dwell periods (either in strain or load control) and observing how these affect the fatigue life of the specimens. The final aim of the activity is to investigate how much detrimental is the effect of the holding periods on the fatigue life in order to validate the creep-fatigue interaction diagram presently adopted in RCC-MRx code for the P91 steel.
\end{abstract}

Key words: P91, creep-fatigue, fatigue damage, creep damage, interaction diagram, RCC-MRx, softening.

\section{Introduction}

Modified 9Cr-1Mo steel is a candidate steel for use in steam generators of nuclear power plants, to achieve a design life of 60 years and operational temperature $550{ }^{\circ} \mathrm{C}$. To ensure the longevity and safe operation of a nuclear power plant, it is essential to prevent creep-fatigue damage and evaluate long-term creep-fatigue life. The linear damage rule is the most well-known method that is typically used to evaluate creep-fatigue life. When the linear sum of fatigue damage and creep damage of a material reaches a critical value, the material fails. Creep damage is typically calculated using time fraction rule or ductility exhaustion approach. The following Eq. (1) [1] is used to evaluate creep-fatigue life by the time fraction rule:

$$
\frac{N}{N_{f(\text { fatigue })}}+N \int_{0}^{t H} \frac{d t}{t R} \leq D
$$

where, $\mathrm{N}=$ Number of cycle to failure in the tested

Corresponding author: Carlo Cristalli, research field: mechanical characterization of nuclear materials. condition; $\mathrm{N}_{\mathrm{f}}($ fatigue $)=$ Number of cycle to failure in LCF conditions; tH: hold time (hrs); tR: creep rupture time (hrs); D: failure criterion. The failure criterion varies in agreement with the adopted standards. Criterion $\mathrm{D}$ is described by a curve in a "fatigue damage - creep damage" plot. A curve that bilinearly connects $(1,0) ;(0.3,0.3)$ and $(0,1)$ coordinates is employed in the RCC-MRx code [2] while the bilinear correlation between $(1,0) ;(0.1,0.01)$ and $(0,1)$ coordinates is adopted in the ASME code [3] (Fig. 1). One of the objectives of the present work is to clarify the discrepancy between the two curves of damage limit. The first and second items in the left side of Eq. (1) are fatigue damage and creep damage, respectively. The time fraction rule requires a creep rupture curve to evaluate creep damage. In ASME III NH [3], JSME [4] and RCC-MRx [2] the calculation procedure of creep damage utilizes the time-fraction approach, while BS-R5 [5] is currently the only code following a "ductility exhaustion" methodology. 


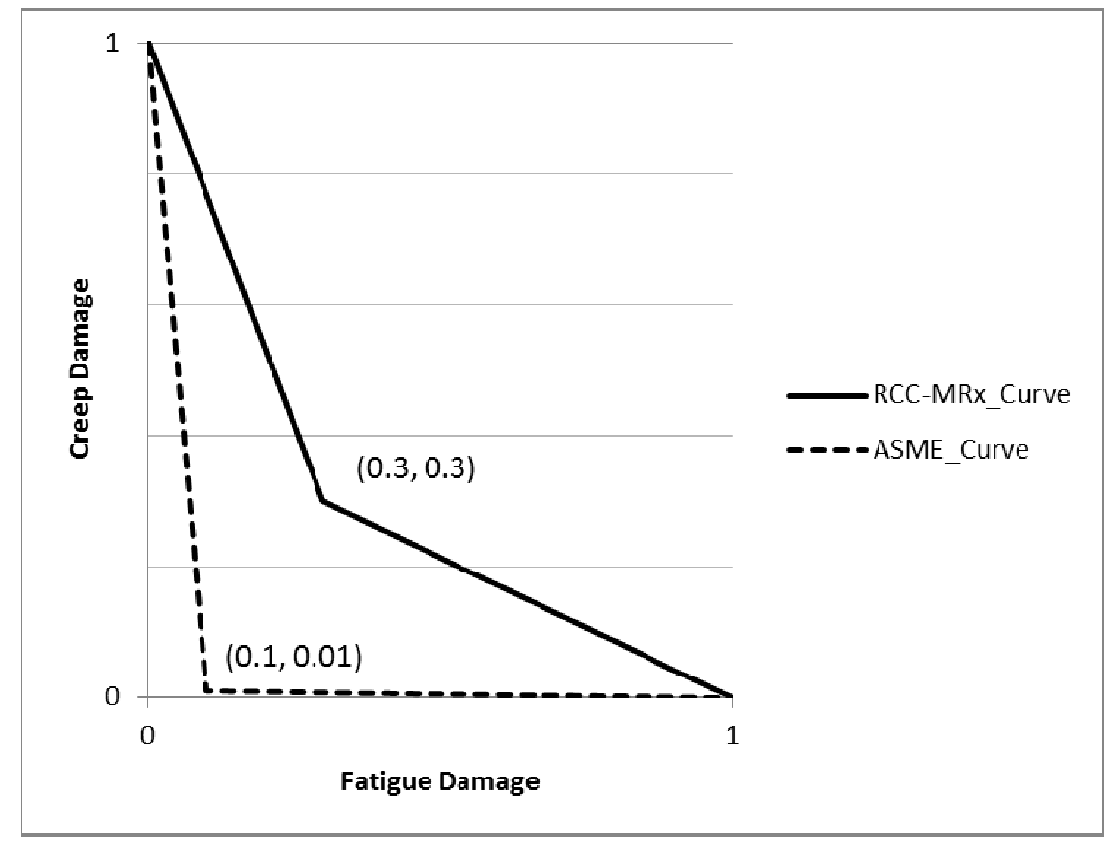

Fig. 1 Creep fatigue Interaction Diagram according to RCC-MRx and ASME.

Concerning the assessment of the creep-fatigue interaction damage, several researchers have previously proposed different approaches based on hysteresis energy [6-9]. Takahashi et al. [9] evaluated creep damage on the basis of inelastic strain-energy density rate and creep-fatigue life using the linear sum of fatigue damage and creep damage. Other works propose innovative methods to evaluate creep-fatigue life on the basis of fracture energy [10-12] considering as time dependent the change in fracture energy. Kimura et al. [13] have proposed a method for predicting creep life called the "region splitting analysis method". In this method, creep rupture data are divided into high-stress and low-stress regions with a boundary condition of one half of the $0.2 \%$ offset yield stress. The region splitting analysis method for creep rupture curves has been taken into account in the 2012 JSME code.

The activity reported in this paper was planned to perform tests on $9 \mathrm{Cr}-1 \mathrm{Mo}$ ferritic/martensitic steel (P91) at $550{ }^{\circ} \mathrm{C}$ combining fatigue cycles and constant tensile holding periods (in both creep-fatigue and relaxation-fatigue mode). The final aim of the activity is to investigate how much detrimental is the effect of the holding periods on the fatigue life in order to validate the creep-fatigue interaction diagram adopted in RCC-MRx code for the P91 steel.

\section{Material and Experimental Procedures}

The experimental set-up used to perform LCF (low cycle fatigue), CF (creep fatigue) and RF (relaxation fatigue) tests consists of the following components: hydraulic press $(100 \mathrm{kN})$, load cell (operation range: \pm $100 \mathrm{kN})$, extensometer (12 mm gauged length) and induction furnace $(6 \mathrm{~kW})$. An extensive optimization process has been carried out on the induction furnace shape in order to keep the temperature profile constant along the gauged length, achieving a tolerance within $\pm 2{ }^{\circ} \mathrm{C}$. A Control Unit with embedded software allows great flexibility in mixing fatigue cycling with creep hold times.

The samples for the tests were manufactured according to ASTM 2714-09 [14] and have undergone statistic quality controls after production in order to verify their fulfilment to specifications in terms of surface roughness and dimensional tolerances. The specimens have been obtained from the $12 \mathrm{~mm}$ thick $9 \mathrm{Cr} 1 \mathrm{MoVNb}$ plate manufactured by Industeel. The 
chemical composition of the material is reported in Table 1. The plate has undergone the following thermal treatments: austenitization $\left(1,060{ }^{\circ} \mathrm{C}-4 \mathrm{~h}\right)$, water quenching, tempering $\left(760^{\circ} \mathrm{C}-3 \mathrm{~h} 20 \mathrm{~min}\right)$ and air cooling.

CF (creep fatigue) and RF (relaxation fatigue) tests differ from standard LCF tests by the interposition of hold-times within the cyclic testing. During CF tests, the stress level is held constant during holding periods. The strain is the controlled parameter in tensile and compressive peaks and it becomes the feedback signal during the hold-time. The load, on the other hand, is the feedback signal in tensile and compressive peaks and becomes the controlled parameter during the hold-time (Fig. 2).

Different from $\mathrm{CF}$ tests, in RF tests, the strain remains the controlled parameter for the whole duration of the cycle, both in tensile and compressive peaks and during the hold-time. The load, on the other hand, remains the feedback signal both in tensile and compressive peaks and during the hold-time (Fig. 3).

In all of the cases, the fatigue strain was controlled

Table 1 Nominal chemical composition of P91 steel supplied by Industeel (wt\%).

\begin{tabular}{|c|c|c|c|c|c|c|c|c|c|c|c|c|c|}
\hline $\mathrm{C}$ & $\mathrm{Si}$ & $\mathrm{Mn}$ & $\mathrm{P}$ & $\mathrm{Cr}$ & Mo & $\mathrm{Ni}$ & $\mathrm{Al}$ & $\mathrm{Cu}$ & $\mathrm{Nb}$ & $\mathrm{Ti}$ & $\mathrm{V}$ & $\mathrm{N}$ & $\mathrm{Fe}$ \\
\hline 0.102 & 0.22 & 0.38 & 0.021 & 8.99 & 0.89 & 0.11 & 0.015 & 0.06 & 0.06 & 0.003 & 0.21 & 0.044 & Bal. \\
\hline
\end{tabular}

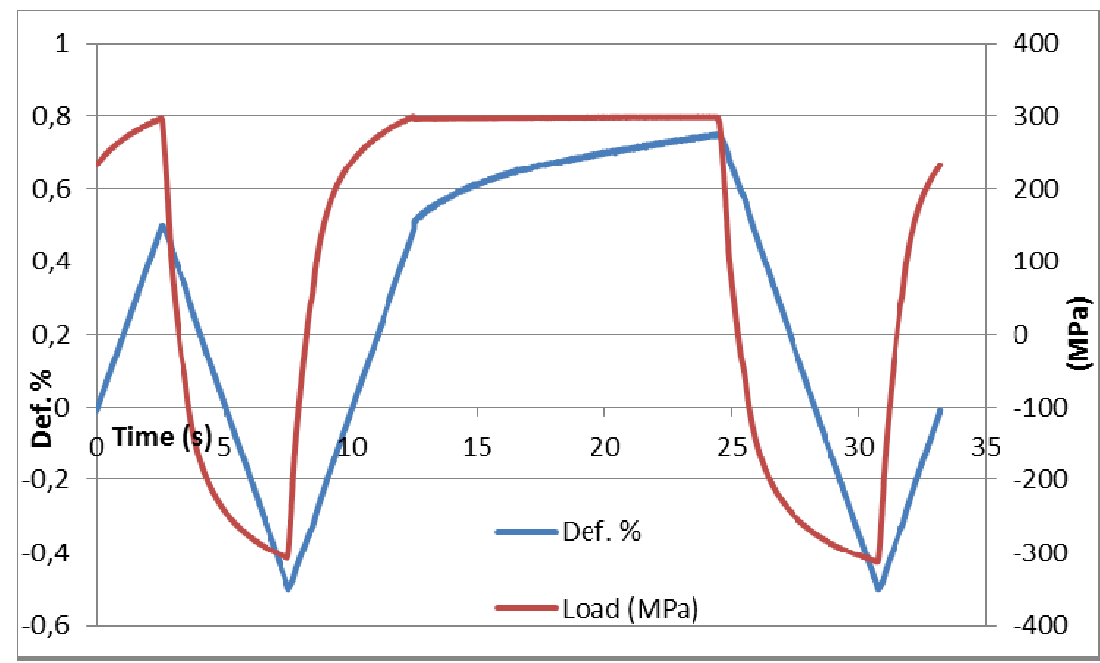

Fig. 2 CF cycle; HT tension 12 s; stress-strain behaviour.

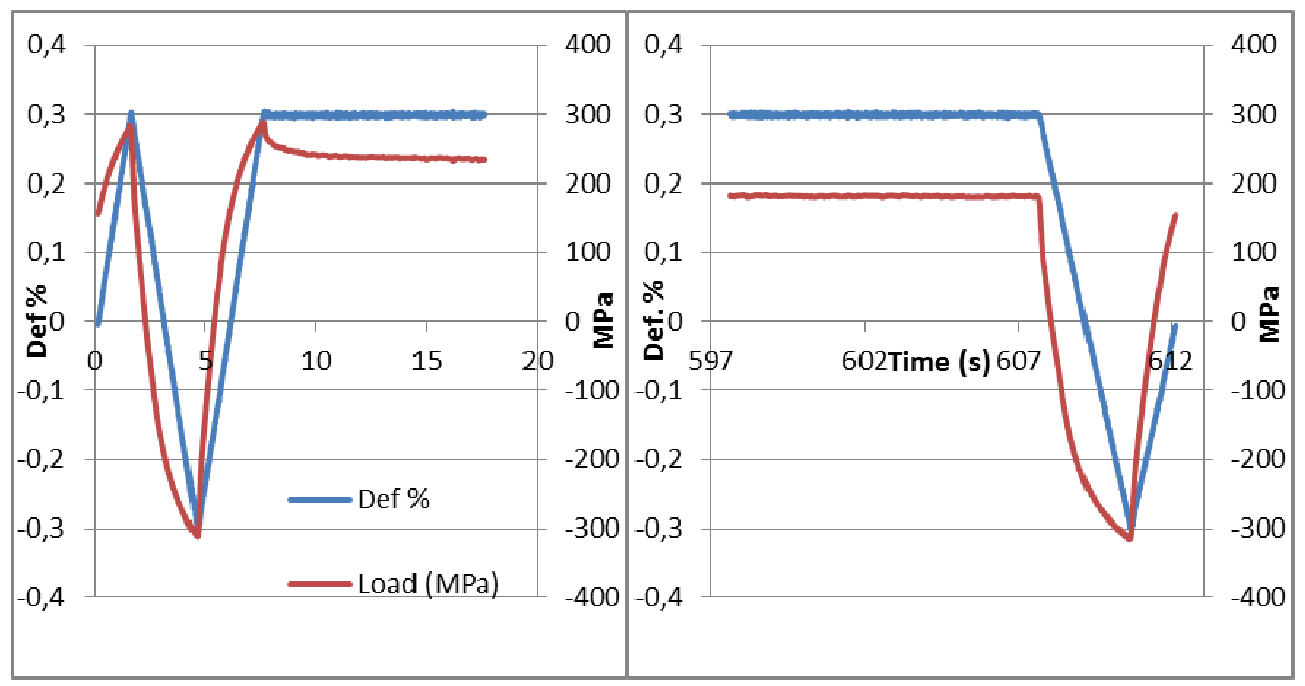

Fig. 3 RF cycle; HT tension 600 s; stress-strain behaviour at the beginning (left), and end of HT (right). 
in terms of total strain (elastic + plastic), which was measured and controlled by the extensometer. The wave shape was triangular and the parameters of the test (total strain range, strain rate and frequency) are listed below:

- $\Delta \varepsilon_{\mathrm{tot}}=1 \%, 0.6 \%$

- $\frac{d \varepsilon}{d t}=2 \times 10^{-3} s^{-1}$

- Frequency $=0.1 \mathrm{~Hz}$

In the following figures the evolution of the hysteresis cycles is reported, both for CF tests (Fig. 4) and for RF tests (Fig. 5). The flattening of the hysteresis cycles in the end of life with respect to the beginning is noticeable. This is due to cyclic softening which is characteristic of ferritic/martensitic steels.
Besides the LCF (low cycle fatigue), the CF (creep fatigue) and the RF (relaxation fatigue) tests, a series of creep rupture tests has been performed, in agreement with ASTM E139-11 standards [15]. The tests have been carried out using single lever MAYES machines with auto-levelling arm device. A three zones P.I.D. controlled furnace and the utilization of $\mathrm{S}$ type thermocouples allow the temperature gradient to be maintained at $\pm 1{ }^{\circ} \mathrm{C}$ along the gauge length.

\section{Experimental Outcomes and Analysis of Results}

A preliminary basic fatigue characterization campaign in the LCF regime was carried out. Two values of fatigue strain have been considered in the

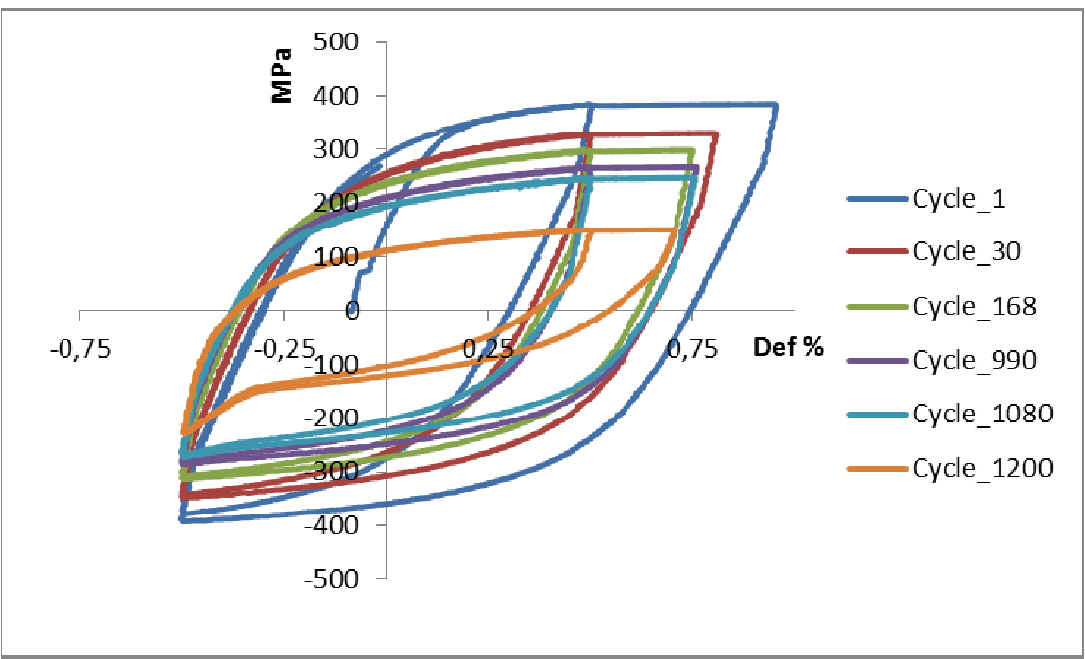

Fig. 4 CF hysteresis cycles; $\Delta \varepsilon=1 \%$; HT tension $12 \mathrm{~s}$.

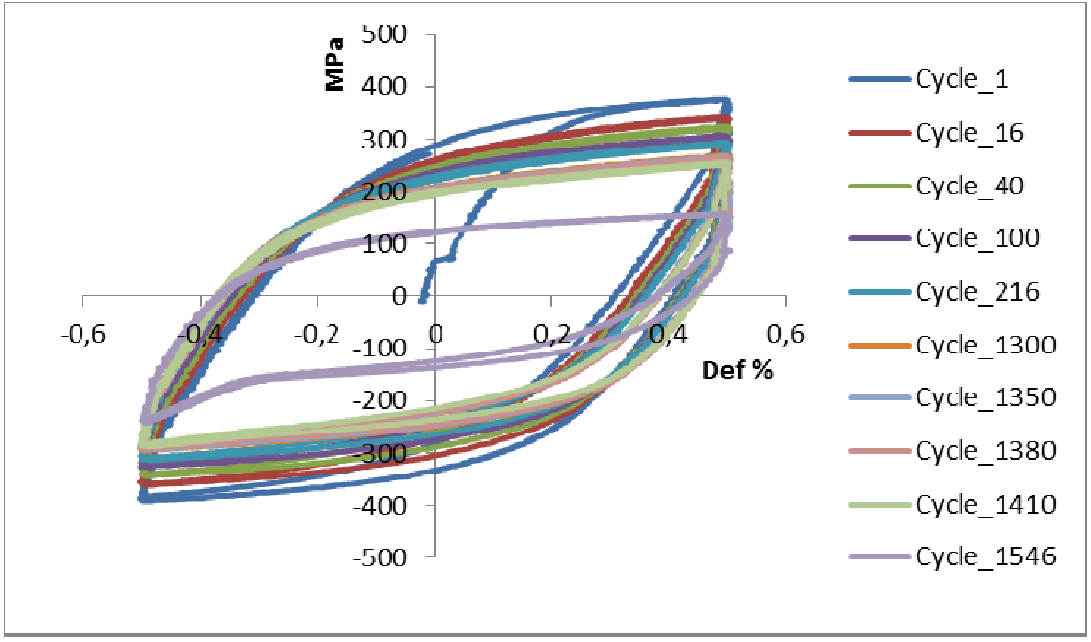

Fig. 5 RF hysteresis cycles; $\Delta \varepsilon=1 \%$; HT tension $600 \mathrm{~s}$. 
experiments: $0.6 \%$ and $1 \%$. The resulting trends of the stabilized load are reported in the next graph (Fig. 6).

Then, for each strain range, several HT (hold time) durations have been chosen based on literature sources [16-18], both in CF and in RF condition. The stress controlled creep-fatigue hold times are expected to be more detrimental than the strain controlled relaxation-fatigue hold times. Thus, concerning the creep-fatigue hold times, the short durations (12 s and $120 \mathrm{~s}$ ) are addressed in the tests performed with $1 \%$ fatigue strain range while the long durations (600 s and $1,800 \mathrm{~s}$ ) are used in the tests with $0.6 \%$ fatigue strain range. These durations of the hold times have been chosen in order to balance the detrimental effects of creep and fatigue for each considered value of the strain range; furthermore the choice was made in agreement with previous published works dealing with creep-fatigue tests on P91 [16-18]. The adopted criterion to estimate the cycles to fracture was that of 25\% load drop, according to ASTM 2714-09 [14]. The pictures of the fractured section of the specimen used in the CF test (600 s HT) are reported in Fig. 7. The appearance of the fracture surface reveals a mixed ductile-fatigue fracture mode.

The test conditions and the corresponding results are summarized in Table 2 in terms of cycles to fracture, corresponding fatigue damage and creep damage. Details of the calculations are reported in the following paragraphs. The complete experimental data of each performed test were made available on the on-line Mat-DB database, managed by JRC [19].

The results of the performed creep rupture tests, in terms of time to rupture, are reported in the graph below (Fig. 8). The achieved experimental points are compared to the minimum and average values for P91, according to RCC-MRx [2]. The experimental points

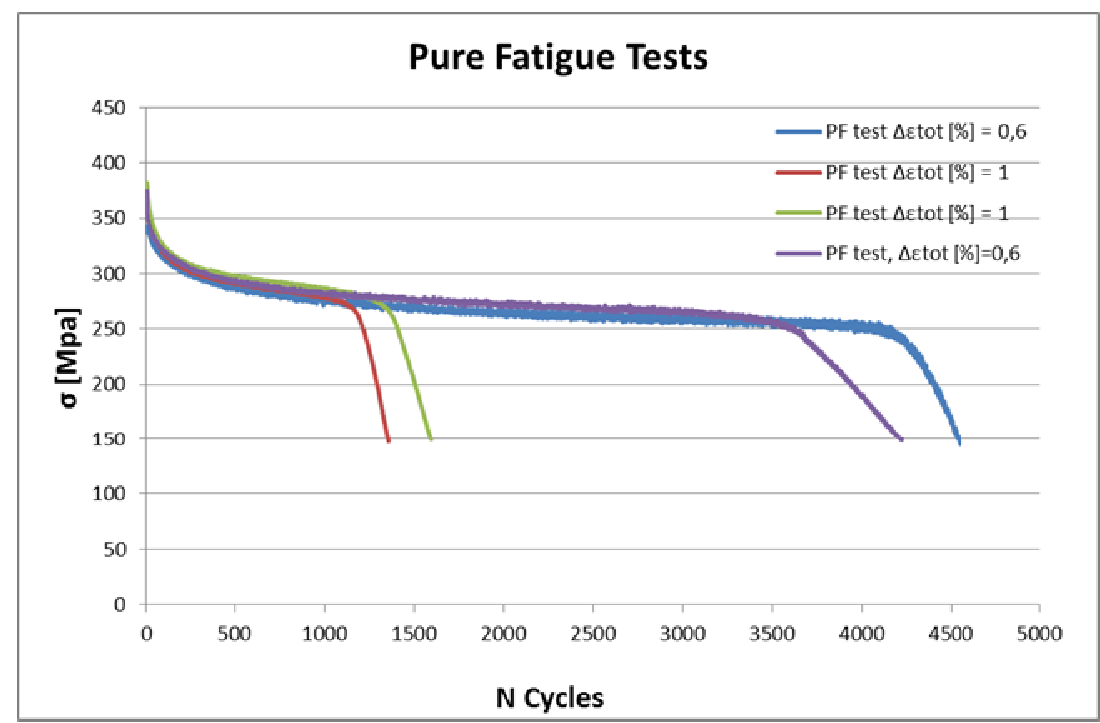

Fig. 6 Trends of the stabilized load for LCF tests (0.6\% and $1 \%$ strain range).
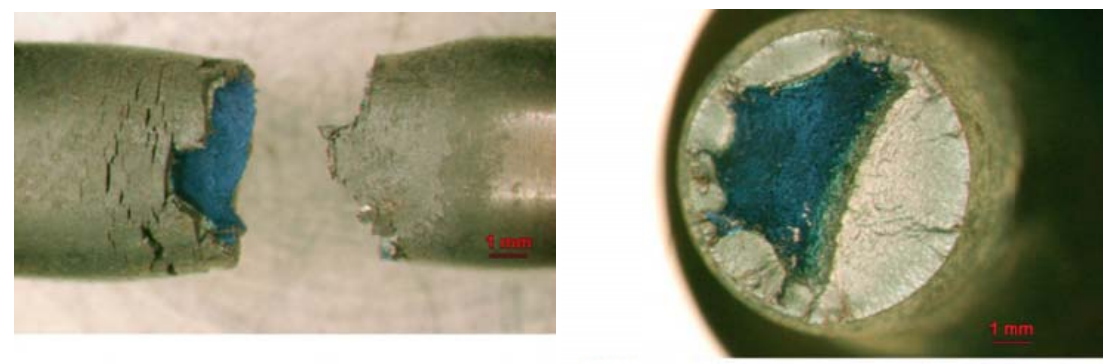

Fig. 7 Fracture of the specimen tested with CF HT $600 \mathrm{~s} ; \Delta \varepsilon=0.6 \%$. 
Table 2 Test matrix with number of cycles to fracture and relative damage achieved in each experimental condition.

\begin{tabular}{|c|c|c|c|c|c|c|c|c|}
\hline Test \# & $\begin{array}{l}\Delta \epsilon_{\text {tot }} \\
{[\%]}\end{array}$ & Type & $\begin{array}{l}\text { Testing } \\
\text { temperature }\left({ }^{\circ} \mathrm{C}\right)\end{array}$ & $\begin{array}{l}\text { Hold Time duration } \\
\text { in tension (min) }\end{array}$ & $\begin{array}{l}\text { Hold Time } \\
\text { duration in } \\
\text { compression(min) }\end{array}$ & $\begin{array}{l}\text { Number of cycles } \\
\text { to failure } \mathrm{N}_{\mathrm{f}}\end{array}$ & $\begin{array}{l}\text { Fatigue } \\
\text { damage }\end{array}$ & $\begin{array}{l}\text { Creep } \\
\text { damage }\end{array}$ \\
\hline 1 & 0.6 & LCF & 550 & - & - & 4,550 & 0.96 & 0 \\
\hline 1 & 0.6 & LCF & 550 & - & - & 4,222 & 0.84 & 0 \\
\hline 2 & 1 & LCF & 550 & - & - & 1,379 & 0.88 & 0 \\
\hline 2 & 1 & LCF & 550 & - & - & 1,590 & 1.02 & 0 \\
\hline 3 & 0.6 & $\mathrm{CF}$ & 550 & 10 & - & 1,620 & 0.34 & 2.47 \\
\hline 3 & 0.6 & $\mathrm{CF}$ & 550 & 10 & - & 1,470 & 0.31 & 2.33 \\
\hline 4 & 0.6 & $\mathrm{CF}$ & 550 & 30 & - & 783 & 0.16 & 3.52 \\
\hline 4 & 0.6 & $\mathrm{CF}$ & 550 & 30 & - & 775 & 0.16 & 2.89 \\
\hline 5 & 1 & $\mathrm{CF}$ & 550 & 2 & - & 902 & 0.58 & 1.45 \\
\hline 5 & 1 & $\mathrm{CF}$ & 550 & 2 & - & 882 & 0.57 & 1.16 \\
\hline 6 & 1 & $\mathrm{CF}$ & 550 & 0,2 & - & 1,145 & 0.73 & 0.63 \\
\hline 6 & 1 & $\mathrm{CF}$ & 550 & 0,2 & - & 1,010 & 0.65 & 0.81 \\
\hline 7 & 0.6 & $\mathrm{RF}$ & 550 & 10 & - & 4,750 & 1 & 0.45 \\
\hline 8 & 0.6 & $\mathrm{RF}$ & 550 & 10 & 10 & 2,534 & 0.53 & $0.45^{*}$ \\
\hline 9 & 1 & $\mathrm{RF}$ & 550 & 10 & - & 1,503 & 0.96 & 1.07 \\
\hline 9 & 1 & $\mathrm{RF}$ & 550 & 10 & - & 1,805 & 1.16 & 1.07 \\
\hline 10 & 1 & $\mathrm{RF}$ & 550 & 30 & - & 1,934 & 1.24 & 0.52 \\
\hline 11 & 1 & $\mathrm{RF}$ & 550 & 10 & 10 & 1,270 & 0.82 & $0.57^{*}$ \\
\hline
\end{tabular}

* The creep damage has not been calculated for the hold times in compression.

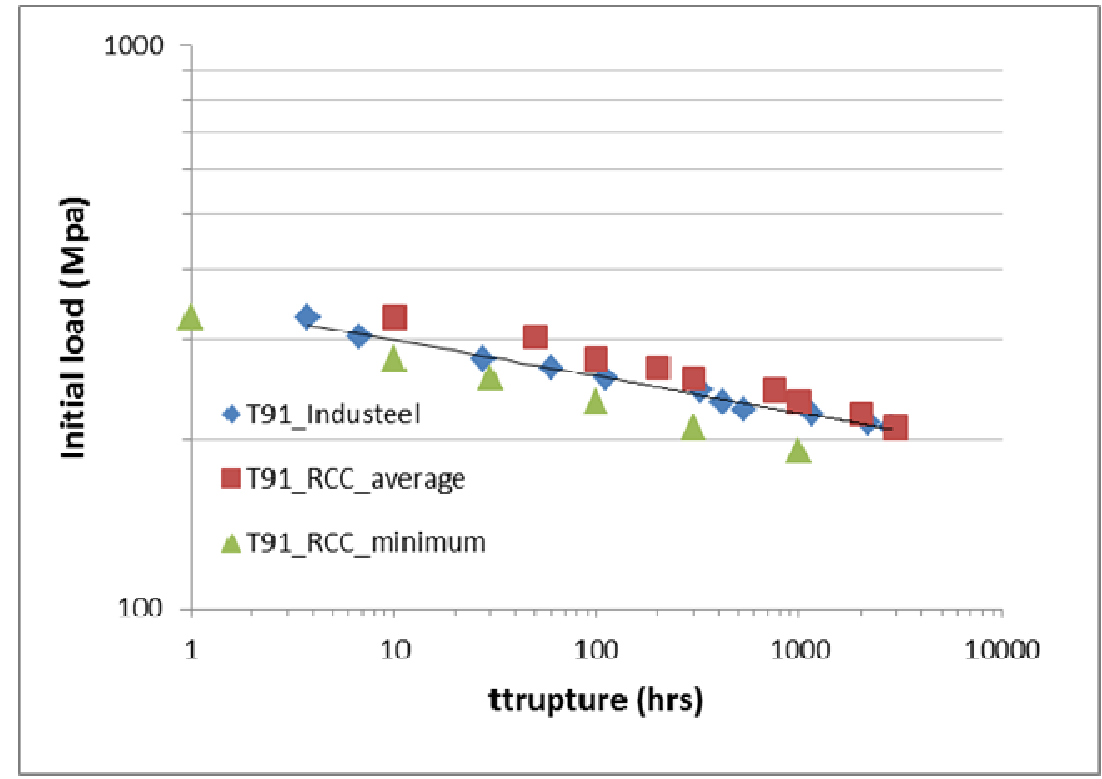

Fig. 8 Times to rupture for the performed creep rupture tests; comparison with RCC-MRx values (average and minimum duration). 


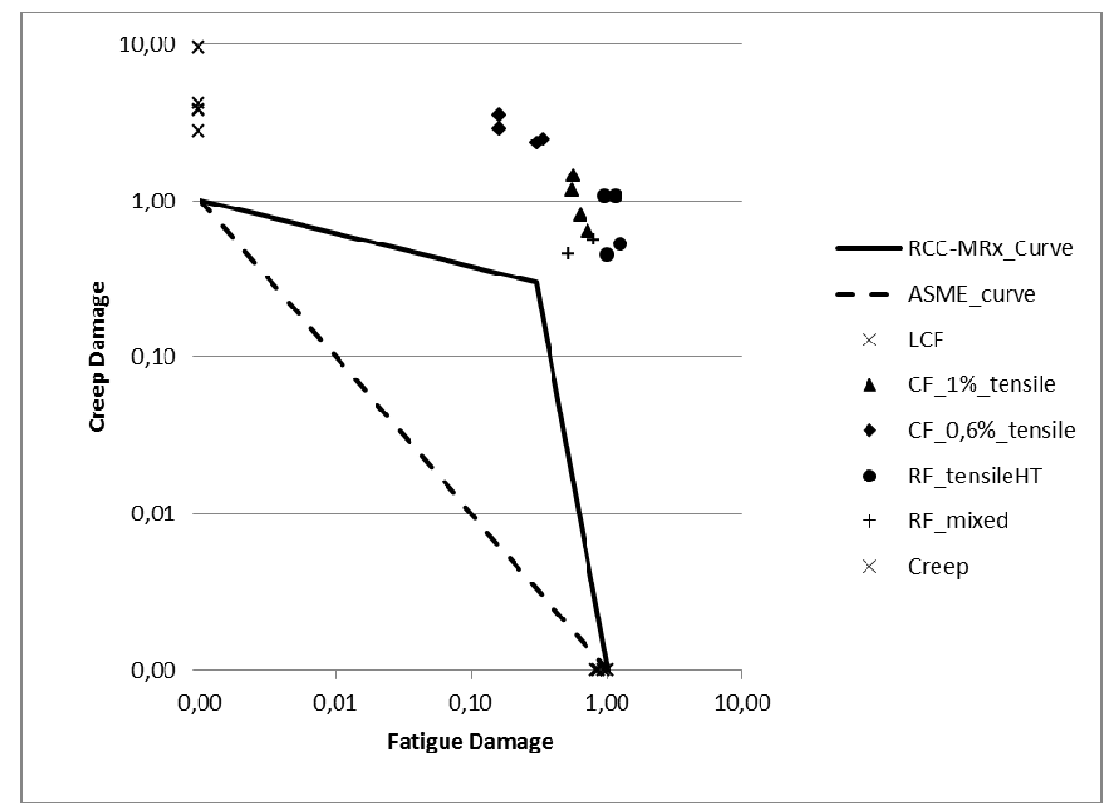

Fig. 9 Creep-fatigue interaction diagram on a double-logarithmic scale with plotted experimental points.

appear to be located in the range between the minimum and the average RCC-MRx values.

\subsection{The Fatigue Damage}

The fatigue damage has been evaluated through the following formulation:

$$
D_{f}=\frac{N_{f}}{N_{\max }}
$$

where, $N_{f}=$ Number of cycles to obtain $25 \%$ of load decrease in each test, according to ASTM E2714-09 [14];

$N_{\max }=$ Maximum number of allowable strain cycles, as determined on the best fit experimental fatigue curve deduced by the RCC-MRx design fatigue curve at $550{ }^{\circ} \mathrm{C}$ multiplied by a factor of 2 in the strain range or a factor of 20 in the number of cycles whatever is the most conservative condition.

\subsection{The Creep Damage}

The creep damage has been evaluated through the following formulation:

$$
D_{C}=\sum_{i=1}^{N_{f}} \frac{T_{h t}}{T_{i}}
$$

where, $T_{h t}=$ Duration of the hold time period in each considered kind of test, ranging from $12 \mathrm{~s}$ to $1,800 \mathrm{~s}$;
$T_{i}=$ Time to rupture corresponding to the load level recorded at each hold time of the test. A fourth degree polynomial function has been used to interpolate the RCC-MRx [2] time to rupture experimental values.

$N_{f}=$ Number of cycles to obtain $25 \%$ of load decrease in each test, according to ASTM E2714-09 [14].

\subsection{The Interaction Diagram}

As we can observe in Fig. 9, CF and RF experimental points fall in the "unsafe" zone of the creep-fatigue interaction diagram, as expected. The interaction curve is plotted according to RCC-MRx [2] and ASME [3] on a double-logarithmic scale diagram.

\section{Conclusions}

Several combinations of hold time durations in different conditions ( $\mathrm{CF}$ and $\mathrm{RF}$ type) have been experimented; the $\mathrm{CF}$ hold times lead to a higher creep damage and a shorter fatigue life than the corresponding RF hold times, as expected. The fatigue life appears deeply affected, in terms of reduction in the number of cycles to failure, by the presence of tensile CF hold times, while no marked life reduction can be noticed due to the RF tensile hold times; this 
test condition appears even beneficial for some of the tested specimens. The most critical tests, namely the closest points to the RCC-MRx curve, are the "RF mixed", namely the ones with same HT duration repeated both in tension and compression. This depends on the fact that creep damage has not been calculated for compressive hold times. The main outcome of this activity concerns the update of the RCC-MRx Code, as long as this experimental campaign resulted successful in validating the creep-fatigue interaction diagram. Every experimental condition, in fact, falls in the "unsafe" zone of the creep-fatigue interaction diagram, according to the RCC-MRx curve.

\section{Acknowledgements}

This work was carried out in the frame of the EU Project MATTER (WP7-Task 7.1-Grant Agreement no. 269706).

\section{References}

[1] Nagae, Y. 2013. Materials Science \& Engineering A 560: 752-8.

[2] AFCEN RCC-MRx Code. 2012. Design and Construction Rules for Mechanical Components of Nuclear Installations.

[3] ASME boiler and pressure vessel code. 2007. Section III Div. 1 Sub-Section NH. New York, USA: ASME.

[4] Onizawa, T., Nagae, Y., Wakai, T., and Asayama, T. 2009. ASME Pressure Vessels Pip. Div. Conf. PVP2009 77984.

[5] R5. 2003. Assessment Procedure for the High Temperature Response of Structures. Gloucester, UK: British Energy.

[6] Ostergren, W. J. 1976. J. Test. Eval. 4: 327-39.

[7] Leis, B. N. 1977. J. Pressure Vessel Technol.: 524-33.

[8] Payten, W. M., Dean, D. W., and Snowden, K. U. 2009. Vessels Pip. Div. Conf. PVP2009-77208. ASME Press.

[9] Takahashi, Y., Dogan, B., and Gandy, D. 2009. Vessels Pip. Div. Conf. PVP2009-77990. ASME Press.

[10] Masanori, A., Nobuhiro, I., Kikuchi, K., and Yasuhiro, E. 2012. "Effect of Ratchet Strain on Fatigue and Creep-Fatigue Strength of Mod.9Cr-1Mo Steel.” Nuclear Engineering and Design 247: 66-75.

[11] Nagae, Y., Takaya, S., and Asayama, T. 2009. J. Solid Mech. Mater. Eng. 3: 449-56.

[12] Nagae, Y., and Takaya, S. 2011. J. Soc. Mater. Sci. Jpn60 (2): 108-15.
[13] Kimura, K., Sawada, K., and Kushima, H. 2010. Vessels Pip. Div. Conf. PVP2010-25297. ASME Press.

[14] ASTM E2714-09-Standard Test Method for Creep-Fatigue Testing.

[15] ASTM E139-11—Standard Test Methods for conducting Creep, Creep-rupture and Stress-Rupture Tests。

[16] Fournier, B. et al. 2011. "Comparison of Variuos 9-12Cr Steels under Fatigue and Creep-Fatigue Loadings at High Temperature." Materials Science and Engineering A 528: 6034-945.

[17] Fournier, B. et al. 2009. "Creep-Fatigue Interactions in a 9 Pct Cr-1 Pct Mo Martensitic Steel: Part I. Mechanical Test Results." Metallurgical and Materials Transactions A 40A: 321-9.

[18] Fournier, B. et al. 2008. "Creep-Fatigue-Oxidation Interactions in a $9 \mathrm{Cr}-1 \mathrm{Mo}$ Martensitic Steel. Part I: Effect of Tensile Holding Period on Fatigue Lifetime." International Journal of Fatigue 30: 649-62.

[19] https://odin.jrc.ec.europa.eu.

[20] Kawasaki, N. et al. 1999. Trans. 15th Int. Conf. Struct. Mech. Reactor Technol. IV: 161.

[21] Asayama, T., and Tachibana, Y. 2007. "Collect Available Creep-Fatigue Data and Study Existing Creep-Fatigue Evaluation Procedures for Grade 91 and Hastelloy XR, DOE/ASME Generation IV Materials Project, a report on Task 5 submitted to ASME ST-LLC, Revision 3 Final Report." JAEA.

[22] Filacchioni, G. 2006. Effects of Hold-Times and Other Testing Parameters on Fatigue Behaviour of Eurofer 97 Base Metal. Final Report for task TW2-TTMS-002 of the EFDA Technology Programme.

[23] Pohja, R., Holmström, S., Nilsson, K.-F., Payten, W., Lee, H.-Y., and Aktaa, J. 2014. "Creep-Fatigue Interaction Rules for P91.” MATTER—Deliverable D4.5, EURATOM FP7 Grant Agreement no. 269706.

[24] Holmstrom, S., Pohaj, R., and Payten, W. 2014. "Creep-Fatigue Interaction Models for Grade 91 Steel. ASTM, Materials Performance and Characterization." DOI: 10.1520/MPC20130054, Published Online.

[25] Pohja, R., Holmström, S., and Lee, H.-Y. 2014. "Recommendation for Creep and Creep-Fatigue Assessment for P91." MATTER-Deliverable D4.6, EURATOM FP7 Grant Agreement no. 269706.

[26] EPRI Techincal Report. 2013. Final Report on Round-Robin Conducted in Support of Standard Test Method for Creep-Fatigue Testing, nr. 3002001719, Electric Power Research Institute.

[27] Holmström, S., and Auerkari, P. 2006. "Robust Prediction of Full Creep Curves from Minimal Data and Time to Rupture Model."Energy Materials, Materials Science \& Engineering for Energy Systems 1: 249-55.

[28] Holmström, S. 2010. "Engineering Tools for Robust 
Creep Modeling." Dissertation, VTT Publications 728, VTT, Espoo, ISBN 978-951-38-7378-3.

[29] Wilshire, B., Scharming, P. J., and Hurst, R. 2009. "A New Approach to Creep Data Assessment." Material Science and Engineering A 510-511: 3-6.

[30] NIMS Atlas of Creep Deformation Property No. D-1, Creep deformation properties of $9 \mathrm{Cr}-1 \mathrm{Mo}-\mathrm{V}-\mathrm{Nb}$ steel tubes for boiler and heat exchangers, 2007.
[31] Tai, A. 2009. "Update and Improve Subsection NH Alternative Simplified Creep-Fatigue Design Methods."

[32] Manson, S. S. 1968. "A Simple Procedure for Estimating High-Temperature Low Cycle Fatigue." Experimental Mechanics 8 (8): 349-55.

[33] Holmström, S., and Auerkari, P. 2013. "A Robust Model for Creep-Fatigue Life Assessment." Mater. Sci. Eng. A 559: 333-5. 